\title{
Experimental Studies ON The InTake Port Of A Diesel EngINe To Determine SwirL
}

\author{
Shankar. $\mathrm{V}^{1}$, Thejaraju $\mathrm{R}^{2}$, Varunraju $\mathrm{V}^{3}$, Amal Chacko $\mathrm{K}^{4}$ \\ ${ }^{1}$ Professor \& Principal Investigator, \\ ${ }^{2}$ Assistant Professor \\ ${ }^{3}$ Research Associate , \\ ${ }^{4}$ Fellowship - Undergraduate Final Year Student \\ Major Research Project -Diesel Engine Research \& Development \\ Department of Mechanical Engineering, Faculty of Engineering, Christ University \\ Bangalore-560074, India \\ ${ }^{1}$ Email: shankar.v@christuniversity.in
}

\begin{abstract}
This paper focuses on experimentalstudies of intake port of a four cylinder diesel engine for different vacuum pressures and valve lift positions. In this study, the cylinder head is experimented through a paddle wheel flow setup, which gives the flow coefficient and swirl number asoutput. Main scope of the work is to understand the flow behaviour through the intake port and finally to determine mean flow coefficient and mean swirl number for different valve lift ratios $L / D$, where $L$ is valve lift and $D$ is bore diameter.
\end{abstract}

\section{KEYWORDS}

Experimental study, Intake port, mean swirl number, mean flow coefficient, L/D ratio.

\section{BACKGROUND INFORMATION}

The research focus is on diesel engine at Mechanical Engineering Department, Faculty of Engineering Christ University, Bangalore and a research proposal was made [1] and Major Research Project (MRP) and in-house funded project has been sanctioned [2] during November 2013 by the Centre of Research Projects, Christ University for a period of three years. The aim and objective in three phases is a) to create a state-of-the-art facility catering to various class of diesel engines in the range of five to hundred HP. Five to ten HP single cylinder engines are used for irrigation and tiller applications whereas sixty to eighty HP class four cylinder engines are used for light motor vehicle applications, b) to evaluate the base line engine characteristics by extensive testing and endurance testing and c) to work on engine modification by going in for Low Heat Rejection (LHR) engine with the idea of providing value added inputs on the existing engine in terms of better Specific Fuel Consumption (SFC) and reduced pollutants. Research work is in good progress and LHR engine is realized by Thermal Barrier Coating ( TBC) of piston crown. A dozen thrust areas are identified for research and one such fascinating area is 3 D Computational Fluid Dynamics (CFD) studies of diesel engine intake port and experimental validation,

Over half a dozen research faculties from various departments - Mechanical, Electrical, Electronics, Mathematics and Chemistry departments participate in this interdisciplinary research program and thirty undergraduate research students participate in the program. The potential spinoff includes: a) faculty pursuing Ph.D. b) Students performing research after prescribed 
academic hours and turning out project/fellowship reports and c) vendor development for associating with research work. For instance, Amado Tools, Bangalore is involved in fabrication related activities and Automotive Research Association of India (ARAI), Pune is involved in testing at the paddle wheel facility [3]

\section{INTRODUCTION}

Research on diesel engine inlet port has been a fascinating area for the last so many decades and continues to be potential area of research in the next generation advanced diesel engines for enhanced mixing and combustion efficiency. There is a need to press into service available tools like Computational Fluid Dynamics (CFD) which is far advanced in terms of millions of grids coupled with a potential solver. The 3 Dimensional (D) CFD analysis, no doubt, gives a lot of information. However, testing is required to calibrate the CFD code so that it would be useful for future design, development and optimization of inlet ports. This, in turn, has a tremendous effect on power, Specific Fuel Consumption (SFC) and exhaust emissions from the engine. CFD has minimized testing efforts; however it does not and cannot eliminate experimental tests. S.K Sabaleand S.B. Sanab [4] has developed a methodology for design of helical inlet port targeting high swirl number of the order of 1.8 and experimentally tested in paddle wheel facility.

Anqi Chen [5] gives a mathematical description and numerical approximation of the flow through inlet port and uses STAR CD CFD code for 3 D CFD analysis. Steady flow in the inlet port and the cylinder is analysed and computation of unsteady flow is highlighted. . Researchers in the past used classical diagnostic techniques, such as hot wire anemometer [6], to investigate engine flow field. For the analytical work, method of characteristics [7]has been used for computation. With the advancement of both software and hardware capabilities, powerful 3 D CFD codes like Fluent, Star CD are used for computation optical diagnostics are employed for experimental verification.

It is recognized that volumetric efficiency and therefore power output could be considerably increased by improving air induction and flow characteristics. Air motion into the cylinder during intake stroke of an internal combustion engine is one of the important factors, which govern the performance of an engine. Swirl is the rotation of charge about cylinder axis and it is used in diesel engines to control air-fuel mixing. Several research studies related to swirl enhancement in IC engines reported that swirl facilitates mixing of air fuel mixture and increases the combustion rate. Furthermore, a high swirl is also not desired, as kinetic energy for the flow is obtained at expense of a reduced volumetric efficiency. Optimum swirl can be created by optimum design of the intake port. An optimal swirl ratio is not only good for optimum combustion, but also for optimal emission reduction[8].

The recent experiments and computations have indicated that the induction generated turbulence, which independent of its initial magnitude, decays by the time of ignition to levels determined by the engine speed. Therefore, it is desirable for the bulk in-cylinder flow to persist through compression, hence releasing its stored kinetic energy at convenient time for combustion to be affected. The controlling parameter is the design and orientation of intake port, in the absence of piston bowl effects. The significant portion of the combustion process takes place by diffusion of flames in a diesel engine. The air-fuel mixing controls the rate of chemical reaction and hence the heat release under this condition. The earlier studies show that the air-fuel mixing is a function of kinetic energies associated with fuel injection and airturbulence[9].

Yufeng $\mathrm{Li}[10]$ proposed new equations for estimation of swirl ratio in which the volumetric efficiency, the compression ratio and pressure drop through intake valve are taken into consideration. Cylinder head of few diesel engines were tested on the steady flow rig and their 
swirl ratios were estimated by these methods. However the result did not show much difference but corrections of the compression ratio, the volumetric efficiency and pressure drop on the swirl ratio were clearly understood.

The focus on present work is to experimentally investigate the swirl number and flow coefficient for different valve lift and vacuum pressure. The test article is typical research engine cylinder head of a four cylinder four stroke seventy two HP diesel engine with a bore of the order of 76 $\mathrm{mm}$ and stroke being $80 \mathrm{~mm}$. Ideally, it is good to test all the four ports individually y to have a statistical correlation of data. However, extensive tests are carried out on one port and 3 D CFD analysis is in progress for validation and for future design purposes.

\section{TyPICAL INLET PORT}

A typical intake port geometry and schematic representation of swirl flow behaviour through the intake port is shown in Fig. 1 and a schematic of steady flow swirl is given in Fig. 2.

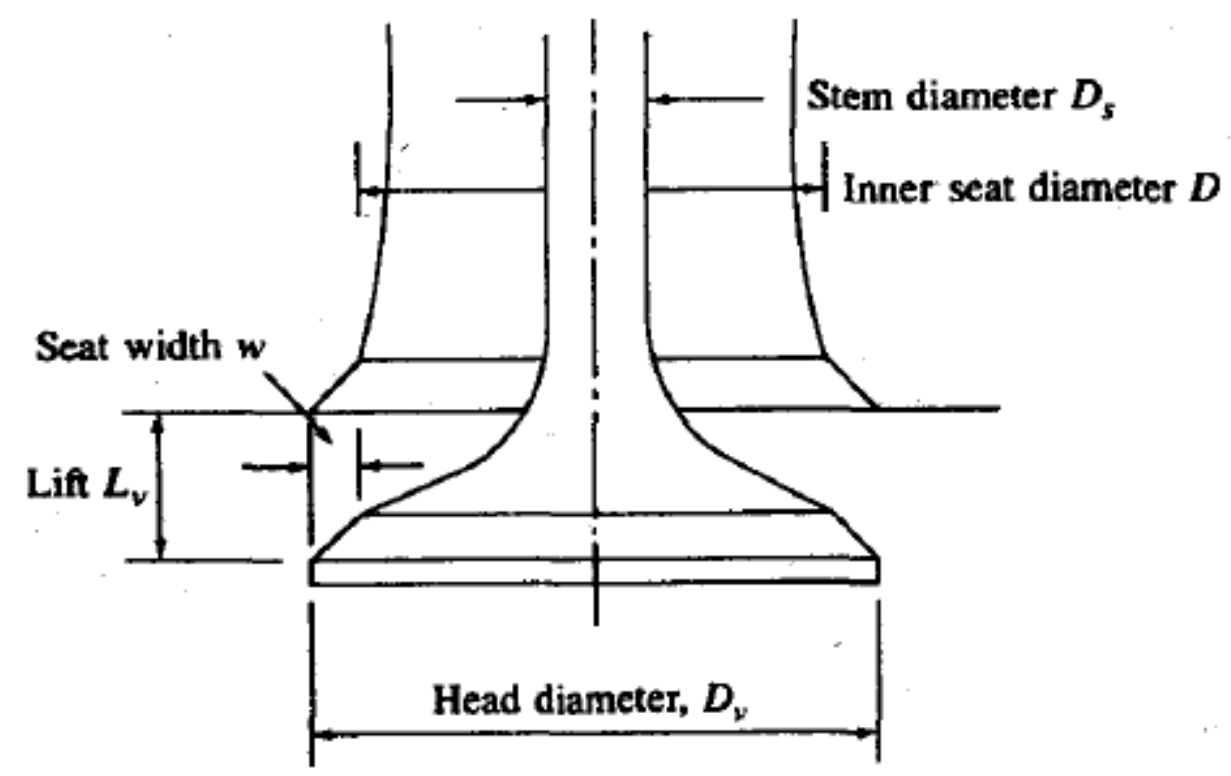

Figure1. Typical inlet port and valve assembly

\section{1 . Parameters Governing Swirl Flow}

It has been observed that in-cylinder flow strongly depends on the inlet port, valve and cylinderhead geometry. Thus in order to better understand the swirl flow behaviour, it is necessary to understand the effect of each design parameters - effect of valve shape, port shape, valve lift and pressure drop on swirl flow. 


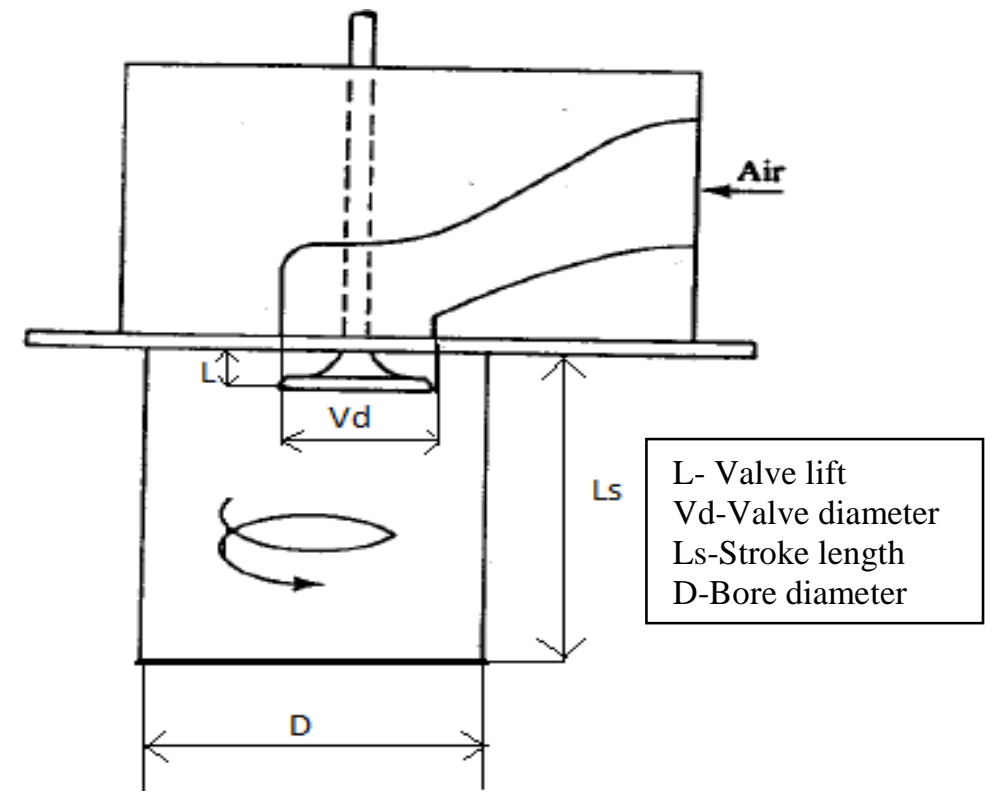

Figure2. Schematic of steady flow swirl

In order to understand the effect of valve shape, the fillet radius of the valve stem, angle of valve head, valve seat angle and sharp corners on the valve and seat have been changed and their influence on air flow characteristics was studied by Tanaka[11]. He found that rounding of sharp corners on the valve and the seat had major influence as rounding of corners between valve and seat made convergent-divergent nozzle which increases the air flow rate.

\subsubsection{Effect of Valve Shape}

The shape of the port near port exit and passage between valve seat and valve head effects the flow pattern. Flow coefficient defined as ratio of measured flow rate and theoretical flow rate increases when the square ratio of port diameter to valve seat diameter were in range of 2.25 to 4.0 as the resistance to the flow decreases studied by Kastner et al.[12].

\subsubsection{Effect of Valve Lift}

Flow pattern inside the inlet valve and cylinder vary with valve lift. In an automobile engine, the valve lift is limited by getting the valve open and shut quickly and is generally one-fifth of valve head diameter. Khalighi[13] observed that at low lifts, the swirl pattern is characterized by double rotation under the valve and flow remains attached to valve head and seat whereas at higher lifts, there is only single rotation and flow separates from valve head. Hence, the discharge coefficient ,$C_{d}$, decreases at low valve lift and then increases with increase in valve lift.

\subsubsection{Pressure Drop}

Flow through intake valve and its seat is similar to flow through venture in which passage converges and diverges. The discharge coefficient decreases as the pressure drop is increased thus limiting the flow rate of air inside the cylinder. At higher valve lifts, the discharge coefficient is independent of pressure drop as flow breaks away from wall and passage has more divergence. 


\section{Test Plan}

To measure the swirl number of the engine under consideration for the following conditions:

a. For various air-flow rate ( with a pressure differential between $200-650 \mathrm{~mm}$ of water)-200, $250,300,350,400,450,500,550,600$ and $650 \mathrm{~mm}$ of water

b. For different intake valve lifts $(0-8 \mathrm{~mm})$

Swirl tests have been carried out in the paddle wheel facility of Automotive Research Association of India (ARAI), Pune. Typical test plan is given in table 1[14,15].

\begin{tabular}{|c|c|c|c|c|c|c|c|c|c|}
\hline \multirow{2}{*}{$\begin{array}{l}\text { Sl. } \\
\text { No }\end{array}$} & \multirow{2}{*}{$\begin{array}{c}\text { Pressure } \\
\text { (mm of } \\
\text { Water) }\end{array}$} & \multicolumn{8}{|c|}{ Valve Lift (mm) } \\
\hline & & V1 & V2 & V3 & V4 & V5 & V6 & V7 & V8 \\
\hline 1 & 200 & 8 & 7 & 6 & 5 & 4 & 3 & 2 & 1 \\
\hline 2 & 250 & 8 & 7 & 6 & 5 & 4 & 3 & 2 & 1 \\
\hline 3 & 300 & 8 & 7 & 6 & 5 & 4 & 3 & 2 & 1 \\
\hline 4 & 350 & 8 & 7 & 6 & 5 & 4 & 3 & 2 & 1 \\
\hline 5 & 400 & 8 & 7 & 6 & 5 & 4 & 3 & 2 & 1 \\
\hline 6 & 450 & 8 & 7 & 6 & 5 & 4 & 3 & 2 & 1 \\
\hline 7 & 500 & 8 & 7 & 6 & 5 & 4 & 3 & 2 & 1 \\
\hline 8 & 550 & 8 & 7 & 6 & 5 & 4 & 3 & 2 & 1 \\
\hline 9 & 600 & 8 & 7 & 6 & 5 & 4 & 3 & 2 & 1 \\
\hline 10 & 650 & 8 & 7 & 6 & 5 & 4 & 3 & 2 & 1 \\
\hline
\end{tabular}

Table 1 Intake Port Test Matrix [11]

\section{PAdDle Wheel SetuP}

The Swirl test facility in ARAI is shown in Fig 3. anda schematic of the test facility is given in Fig 4.

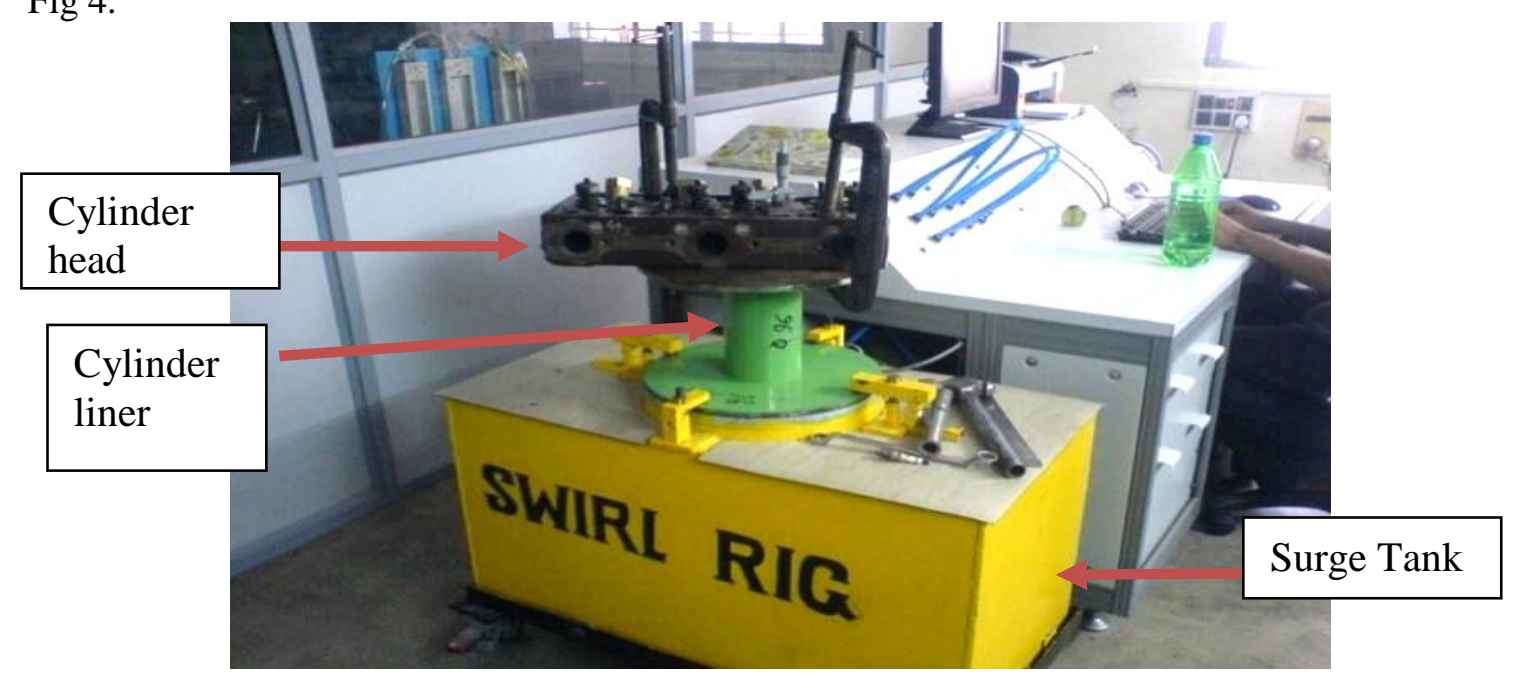

Figure3. Swirl Flow Rig Setup [3] 


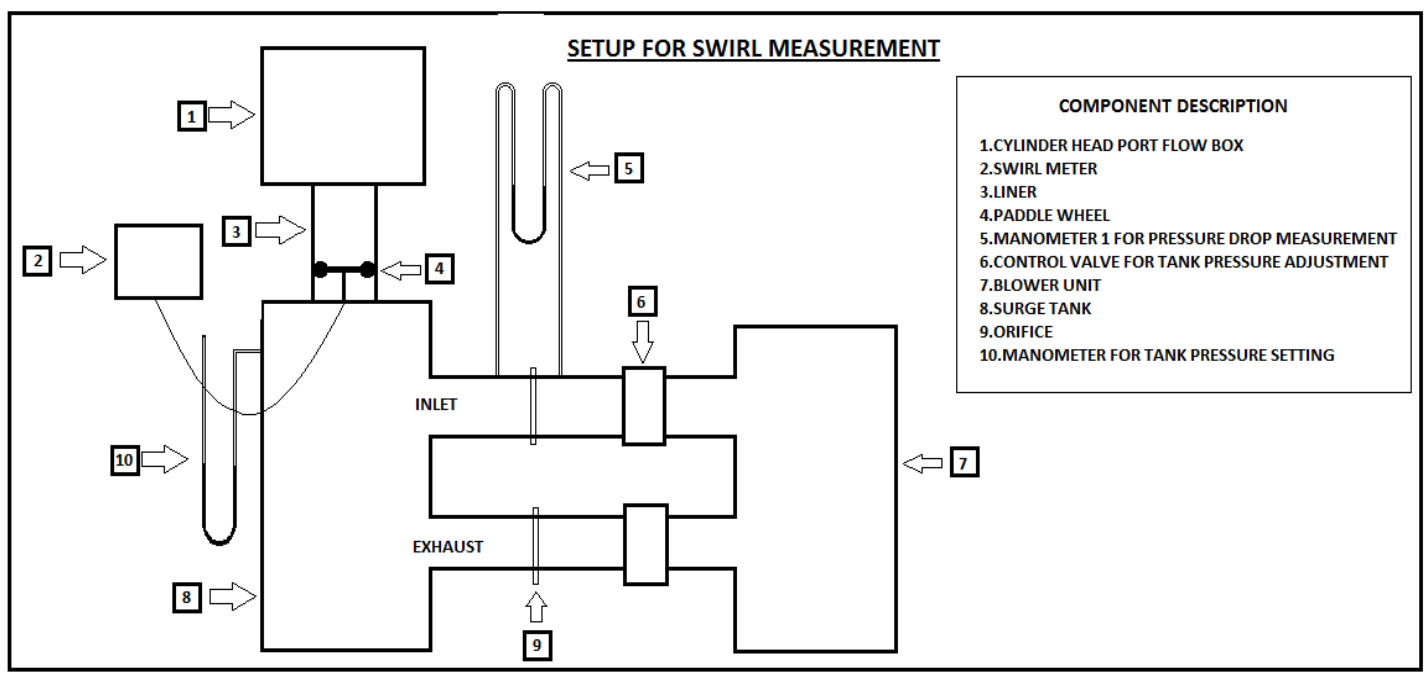

Figure4.A Schematic of paddle wheel facility at ARAI, Pune

Air swirl speed or momentum in the cylinder generated by intake ports is generally measured on a steady flow rig. The variable frequency drive blower provides an air flow source for the steady flow rig. The cylinder head to be measured is placed on the rig bench and is centred well with cylinder dummy which has diameter identical to engine bore. The steady flow starts from maximum valve lift up to $1 \mathrm{~mm}$ of valve lift.

\subsection{Test Rig Components and Test Procedure}

The main components of the test rig include:

1. Cylinder head port

2. Swirl meter

3. Liner

4. Paddle wheel

5. Manometer 1 for pressure drop measurement

6. Control valve for tank pressure adjustment

7. Blower unit

8. Surge tank

9. Orifice

10. Manometer 2 for tank pressure setting

To test the inlet port at various valve lifts, the following steps were followed:

i. The valve was set at $8 \mathrm{~mm}$ valve opening by giving a rotation to metric screw and noting the reading on dial gauge mounted upon the valve stem.

ii. Blower was started with control valve partially opened.

iii. The differential pressure across the tank was observed in the U-tube water manometer. It was monitored from $200 \mathrm{~mm}-650 \mathrm{~mm}$ of water by operating the control valve.

iv. The final readings were taken after waiting for 15 minutes so that the flow could be maintained steady. Various reading were noted, namely, lift (L) in mm, mass flow rate (m) in lit/sec. and paddle wheel speed (nD) in rpm. 
The readings were taken at each interval of valve lift, starting from $8 \mathrm{~mm}$ to $0 \mathrm{~mm}$ for each valve of pressure ranging from $200 \mathrm{~mm}-650 \mathrm{~mm}$ of water following the same procedure.

In order to co-relate the swirl flow test rig with actual engine following assumption are considered:

- Air flowing through intake ports in real engine and on steady flow rig is assumed to be compressible and isentropic.

- Swirl motion in the cylinder of both real engine and steady flow rig is rigid body vortex.

- Pressure drop as air flows through intake ports is constant during the intake process in the real engine i.e. air velocity passing through valve seat is constant during intake process.

\subsection{Formulae}

The flow coefficient of the intake port at each valve lift is defined as,

$$
\mathrm{C}_{\mathrm{f}}=\frac{\dot{m s}}{\rho_{s} * A * V_{s}}(1)
$$

Where $\mathrm{C}_{\mathrm{f}}$ is the flow coefficient; $m s$ is the mass flow rate;

$\rho_{s}$ is the air density at valve seat;

$A$ is the inner valve area of the valve seat;

$\mathrm{V}_{\mathrm{s}}$ is the velocity when air passes through the intake valves;

$$
A=\frac{\pi}{4} * d^{2}
$$

$$
V_{s}=\sqrt{\frac{2 \Delta P_{s}}{\rho_{s}}}
$$

Where $\mathrm{d}$ is the diameter of intake valve seat;

$\Delta P_{S}$ is the pressure difference between cylinder dummy and atmosphere.

The swirl intensity in the cylinder dummy at each valve lift is defined as:

$$
R_{s}=\frac{n_{d}}{n}
$$

Where, $R_{\mathrm{s}}$ is the swirl ratio at each valve lift

$\mathrm{n}_{\mathrm{d}}$ is the swirl speed (rev per min) i.e. pedal wheel speed

$\mathrm{n}$ is the relative engine speed when the mass flow rate in real engine is equal to mass flow rate in the steady rig. 


\section{RESUlts AND DiscusSiONS}

The current study involves determination of mean swirl number, mean flow coefficient, paddle wheel speed, and dischargecoefficient and flow rate with respect to L/D non dimensional ratio for various pressures. The results are presented and discussed below:

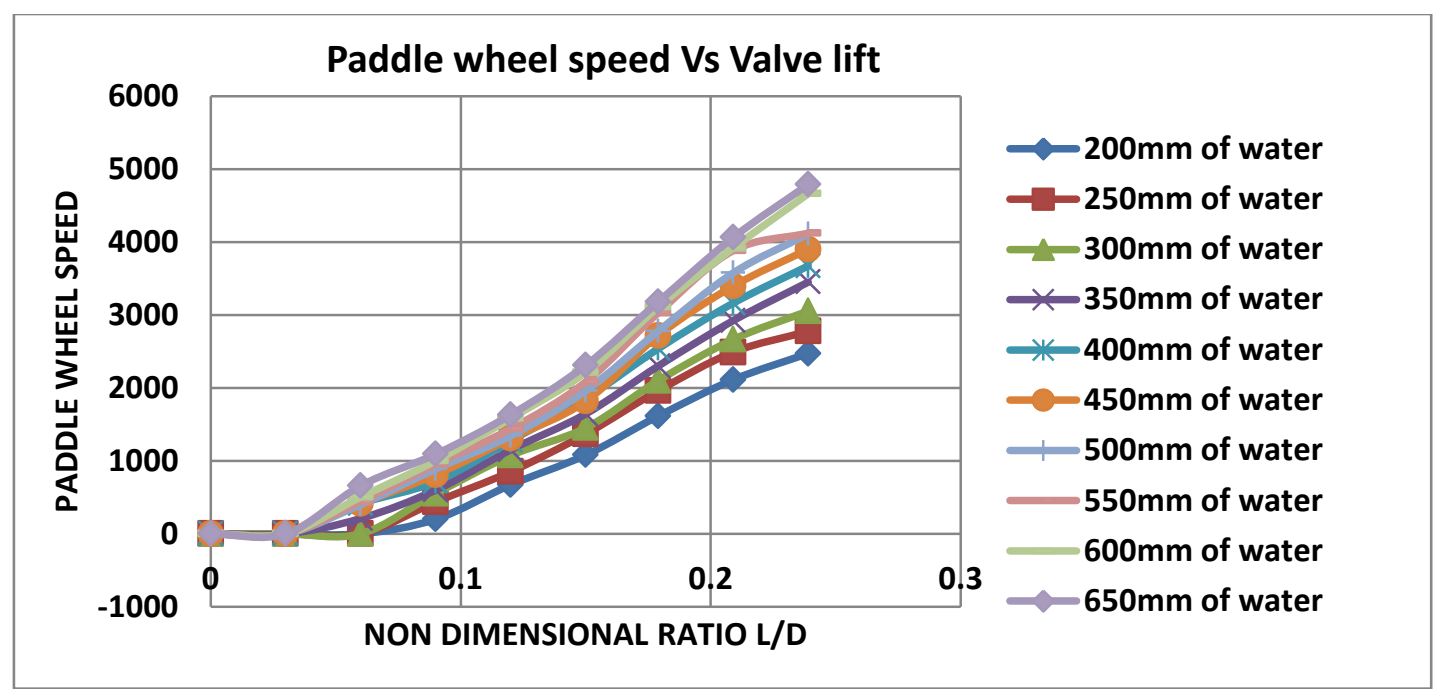

Figure 5. Paddle wheel speed Vs Valve lift ratio

The variation of the paddle wheel speed with respect to different pressures of water has been plotted in figure 5. From the above figure, it can be obsreved that the variation of paddle wheel speed with respect to non dimentional ratio L/D at different pressures are uniform and linear behaviour. Thus we can understand that with increase in pressure drop the circumferential velocity increases which increases the pedal wheel speed and it increases linearly with valve lift.

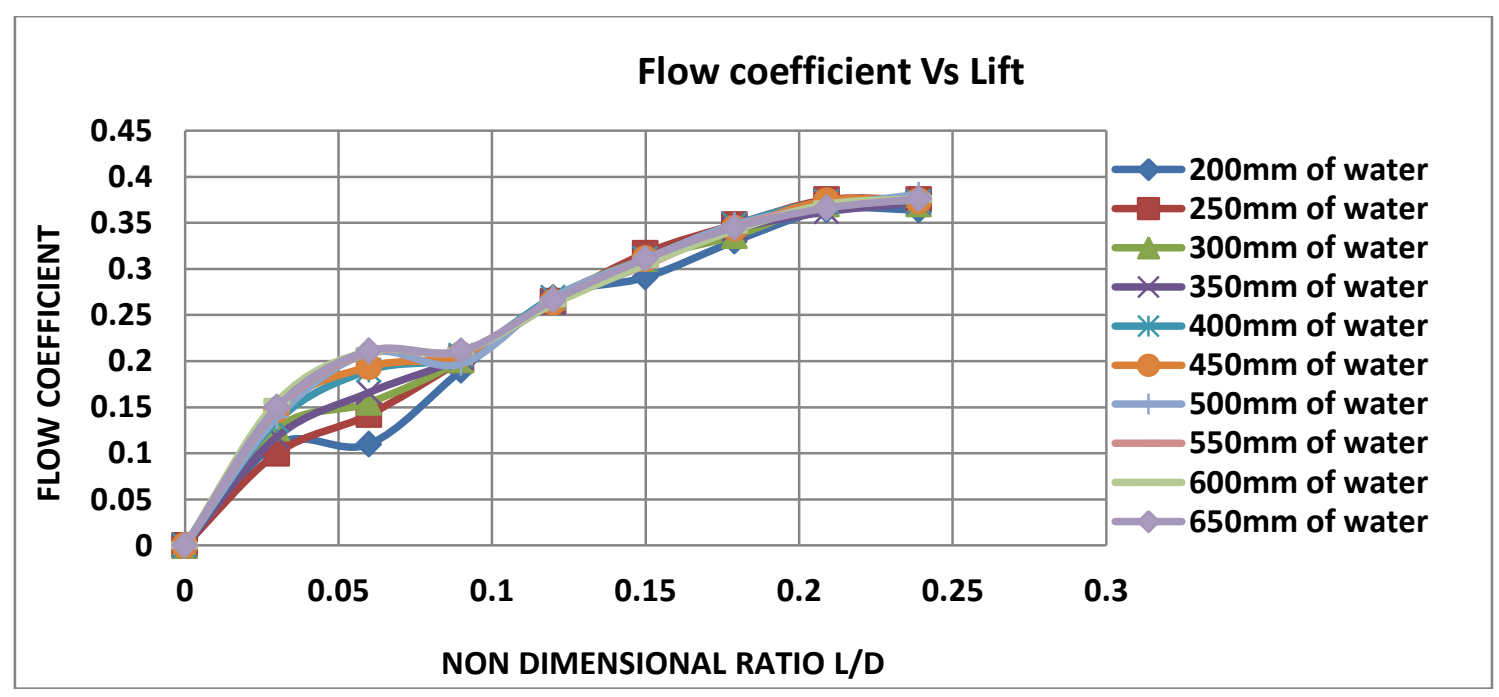

Figure 6. Flow coefficient Vs Valve lift ratio

Fig 6.shows the variation of flow coefficient versus L/D ratio. From the above figure, the variation of non dimentional ratio between 0.03-0.09 results in distortion of the flow coefficient 
whereas from L/D ratio of $0.10-0.22$, the flow coefficient is independent of pressure drop.Therefore in general the flow coefficient is approximately independent of pressure drop except at small valve lift, where it increases with pressure drop.

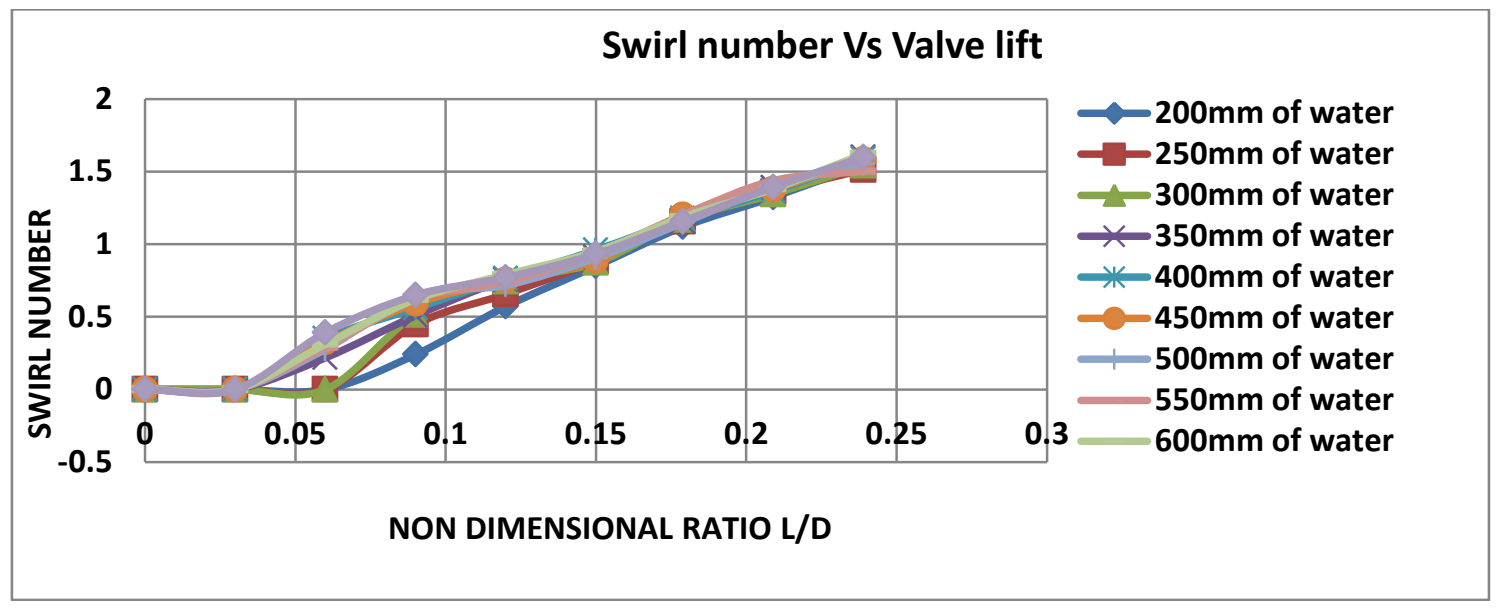

Figure 7. Swirl number Vs Valve lift ratio

The variation of the swirl number with respect to different pressures of water has been plotted in figure 7. From the above figure, the variation of non dimentional ratio between $0.05-0.12$ results in distorting the swirl number from 0-0.7 as disturbance is created for the flow.Thus we can understand that at lower valve lift, the swirl number increases with pressure drop but at higher lifts, the swirl number is independent of pressure drop.

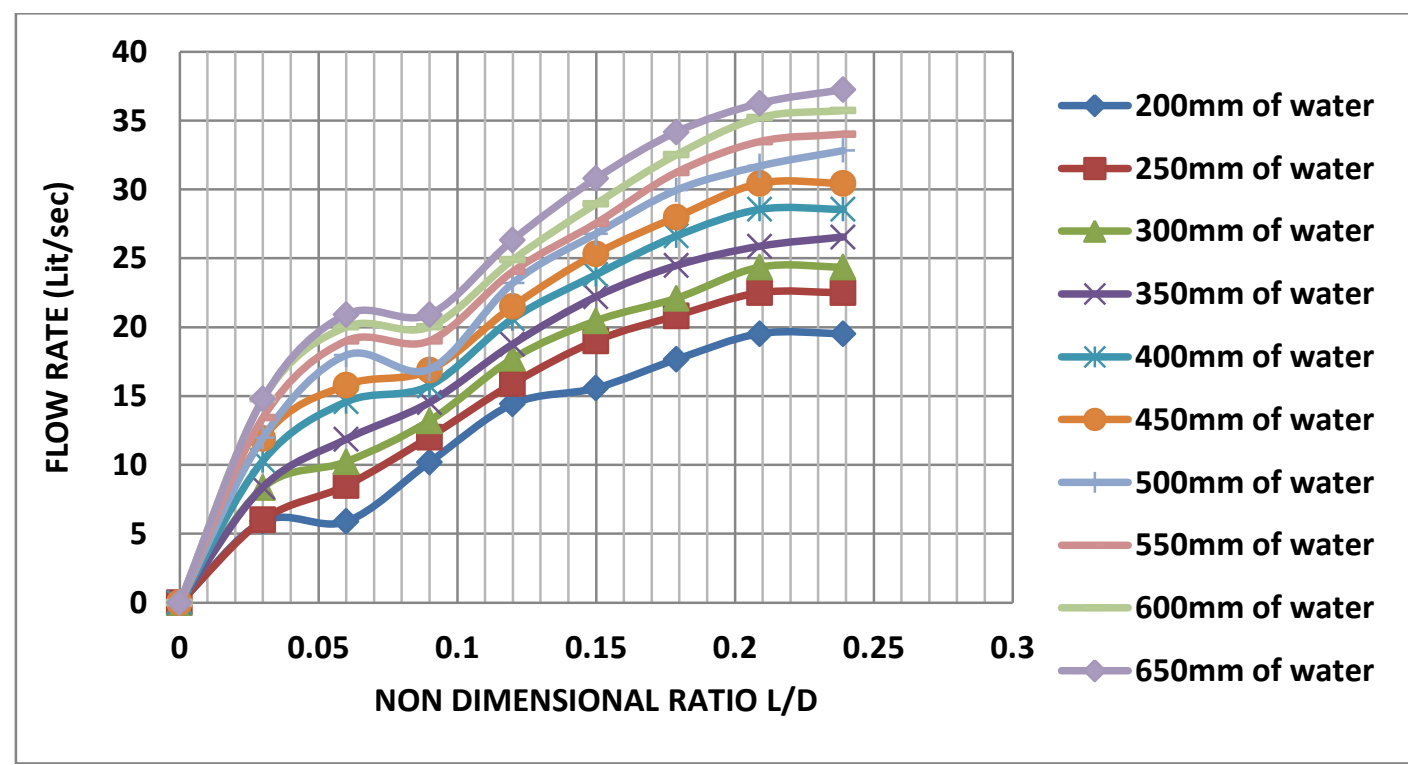

Figure 8. Flow rate Vs Valve lift ratio

From figure 8.it may be noted that the port allows the flow from $5 \mathrm{l} / \mathrm{s}$ to $38 \mathrm{l} / \mathrm{s}$ for the $\mathrm{L} / \mathrm{D}$ ratio ranging from 0.015 to 0.243 . For initial half range of $\mathrm{L} / \mathrm{D}$ ratio, the flow increases linearly and for the remaining half the increase is moderate and then it becomes asymptotic. At lower valve lift, the flow remains attached to the valve head and valve seat. But at higher lifts the flow separates from valve seat. Thus at higher valve lift, the rate of increase of flow rate decreases and becomes asymptotic. 


\section{Conclusion}

The current study involves familiarization of flow characteristics in the intake port shape by using paddle wheel setup and therefore getting an insight into their relative merits and demerits. Some of the conclusions obtained from above study are as follows:

From the above results we can conclude that the maximum swirl number, flow rate, paddle wheel speed has been obtained for the highest L/D ratio. For the L/D ratio of less than 0.05 there was no reaction of paddle wheel speed and swirl number. The pedal wheel speed increases with increase in $\mathrm{L} / \mathrm{D}$ ratio and also with increase in pressure drop. Howeverfor initial half range of $\mathrm{L} / \mathrm{D}$ ratio, the flow increases linearly independent of pressure drop and for the remaining half the increase is moderate and then it becomes asymptotic. Since asvalve lift increases, there is flow separation taking place between valve seat and valve headand thus the flow area remains constant even with increase in valve lift and hence the flow becomes asymptotic. The experimental results would be compared with the $3 \mathrm{D}$ CFD analysis that is in progress.

\section{REFERENCES}

[1] Shankar. V, Experimental Studies on Seventy Two HP Class Four Cylinder Diesel Engine, Research Proposal, Report no. CUFE/MRP/001/2013, Christ University, Sep 2013.

[2] D.N.S Kumar, Approval of Major Research Proposal on Experimental Studies on Seventy Two HP Class Four Cylinder Diesel Engine, Nov 2013.

[3] Ashish Jain, Ramdasi and N. V. Marathe, Port Swirl and Flow Measurement on Research Engine Cylinder Head for Christ University, Bangalore, Report No. PTE/15-16/CHRISTU/R-XXX, Feb 2016.

[4] S.K. Sabale and S. B. Sana, “ Design and Analysis of Intake Port of diesel Engine for Target Value of Swirl, American Journal of Mechanical Engineering, Vol. 1, No. 5, 2013, pp 138-142.

[5] AnqiChen,"Application of Computational Fluid Dynamics to the Analysis of Intake Port Design in Internal Combustion Engines", A Ph.D Thesis, Loughborough University of Technology, June 1994.

[6] Amann, C.A., "Classical Combustion Diagnostics for Engine Research", SAE paper no: 850395, 1985.

[7] Annand, W.J.D., and Roe, G.E., "Gas flow in the internal combustion Engine, Yeovil: Foulis, 1974.

[8] MohdTaufik Bin AbdKadir, "Intake Port Flow Study on Various Cylinder Head Using Flow bench", University Malaysia Pahang.

[9] Heywood J. B., Internal Combustion Engine Fundamentals, McGraw-Hill, Inc., USA, 1988.

[10] Yufeng Li., "A New Estimation of Swirl Ratio from Steady Flow Rig Testing," SAE Technical Paper 201487-01-25, 2014, doi:10.4271/2014-01-2587.

[11] Tanaka, "Air Flow Through Suction Valve of Conical Seat", Aeronautical Research Institution report, Tokyo Imperial University, No. 50, pg: 259, 1929.

[12] Kastner, L.J., William and white, "Poppet Inlet Valve Characteristics and Their Influence on the Induction process", Proceedings of Mechanical Engineering, Vol.178, pp.955-975, 1963-1964.

[13] Khalighi, B.," Intake Generated Swirl and Tumble Motions in a 4-valve Engine with Various Intake Configurations- FVarunRalow Visualization and Particle Tracking Velocimetry", SAE paper $892096,1989$.

[14] Shankar. V, Varunraju et.al, Intake Port Test Plan, Christ University Faculty of Engineering CUFE, Document No.: CUFE/MECH/OPI/0010

[15] Amal Chacko," An Experimental Study on Intake Port Swirl Generation Using Steady Flow Test Rig”, B.Tech Project Report, Christ University, March 2016. 